\title{
Polymer-lipid hybrid anti-HER2 nanoparticles for targeted salinomycin delivery to HER2-positive breast cancer stem cells and cancer cells
}

This article was published in the following Dove Press journal:

International Journal of Nanomedicine

18 September 2017

Number of times this article has been viewed

\author{
Jun $\mathrm{Li}^{1, *}$ \\ Wenqing $X u^{2, *}$ \\ Xiaoli Yuan ${ }^{3, *}$ \\ Huaiwen Chen ${ }^{3}$ \\ Hao Song ${ }^{1,4}$ \\ Bingquan Wang ${ }^{5}$ \\ Jun $\operatorname{Han}^{5}$
}

'College of Pharmacy, Liaocheng University, Liaocheng, Shandong,

${ }^{2}$ Railway Police College, Zhengzhou, ${ }^{3}$ Department of Cadre Health Care, Nanjing General Hospital of Nanjing Military Command, Nanjing, Jiangsu,

${ }^{4}$ Centre for Stem Cell \& Regenerative Medicine, Liaocheng People's Hospital, ${ }^{5}$ Institute of Biopharmaceutical Research, Liaocheng University, Liaocheng, Shandong, China

*These authors contributed equally to this work
Correspondence: Jun $\mathrm{Li}$ College of Pharmacy, Liaocheng University, I Hu'nan Road, Liaocheng, Shandong 252000, China

Tel +86 6358239133

Fax +866358239680

Email think.a@I63.com

Jun Han

Institute of Biopharmaceutical Research, Liaocheng University, I Hu'nan Road, Liaocheng, Shandong 252000, China

Tel/fax +86 6358239136

Email junhanmail@।63.com
Purpose: Breast cancer stem cells (CSCs) are responsible for the initiation, recurrence, and metastasis of breast cancer. Sufficient evidence has established that breast cancer cells can spontaneously turn into breast CSCs. Thus, it is essential to simultaneously target breast CSCs and cancer cells to maximize the efficacy of breast cancer therapy. HER2 has been found to be overexpressed in both breast CSCs and cancer cells. We developed salinomycin-loaded polymer-lipid hybrid anti-HER2 nanoparticles (Sali-NP-HER2) to target both HER2-positive breast CSCs and cancer cells.

Methods: The antitumor activity of Sali-NP-HER2 constructed by conjugating anti-HER2 antibodies to polymer-lipid salinomycin nanoparticles was evaluated in vitro and in vivo.

Results: Sali-NP-HER2 efficiently bound to HER2-positive breast CSCs and cancer cells, resulting in enhanced cytotoxic effects compared with non-targeted nanoparticles or salinomycin. In mice bearing breast cancer xenografts, administration of Sali-NP-HER2 exhibited superior efficacy in inhibiting tumor growth. Sali-NP-HER2 reduced the breast tumorsphere formation rate and the proportion of breast CSCs more effectively than non-targeted nanoparticles or salinomycin alone.

Conclusion: Sali-NP-HER2 represents a promising approach in treating HER2-positive breast cancer by targeting both breast CSCs and cancer cells.

Keywords: nanoparticles, breast cancer, cancer stem cells, salinomycin, HER2

\section{Introduction}

Breast cancer is a leading cause of death among women globally and the second most common cancer in both sexes. ${ }^{1,2}$ Overall survival is significantly hampered by cancer drug resistance, recurrence, and metastasis, ${ }^{3,4}$ and breast cancer stem cells (CSCs) are considered responsible for these factors. ${ }^{5,6}$ Thus, eliminating breast CSCs may increase the therapeutic efficacy of breast cancer.

Salinomycin, which reduces the proportion of breast CSCs, has been reported to be a potent drug against breast $\mathrm{CSCs}^{7-9}$ The anti-CSC mechanisms of salinomycin include blockade of the Wnt/ $\beta$-catenin pathway. ${ }^{9,10}$ Sufficient evidence has suggested that breast cancer cells could spontaneously and stochastically turn into CSCs de novo. ${ }^{11,12}$ Hence, the simultaneous elimination of both CSCs and cancer cells could maximize therapeutic efficacy against cancer. ${ }^{13-15}$ Although salinomycin has shown potent activity toward CSCs, its cytotoxic effects on cancer cells are not substantial. ${ }^{13-15}$ Improving the cytotoxic effect of salinomycin on breast cancer cells would be a significant breakthrough. 
Targeted nanoparticles have become powerful drug delivery systems, since they can improve the potency of chemotherapy drugs against cancer cells overexpressing antigens such as HER2. ${ }^{16-20}$ HER2 overexpression occurs in $25 \%-30 \%$ of human breast cancers and leads to a particularly aggressive form of the disease. ${ }^{21}$ Thus, HER2 is a validated target in breast cancer. Several studies have indicated that, in HER2-overexpressing cancer cell lines, breast CSCs presented increased HER2 levels compared with breast cancer cells, and HER2 contributed to the tumorigenesis and invasion of breast CSCs. ${ }^{8,22}$ Trastuzumab, the anti-HER2 antibody, was shown to effectively target breast CSCs in HER2-positive cancer cells. ${ }^{8}$ Thus, since HER2 is overexpressed in both breast CSCs and cancer cells, we hypothesize that HER 2 could be a potential target to mediate effective delivery of salinomycin to breast CSCs and cancer cells.

A large number of nanoparticles have been approved for clinical use or have entered clinical trials. ${ }^{16}$ Nanoparticles of biodegradable polymers and liposomes are the two dominant categories. Nanoparticles of biodegradable polymers are characterized by their controlled drug release, superior stability, and drug-loading capacity, while their biocompatibility is not as good as that of liposomes. However, the clinical use of liposomes is limited by uncontrollable drug release, instability, and insufficient drug loading. ${ }^{23}$ Novel polymer-lipid hybrid nanoparticles that combine the advantages and overcome the disadvantages of the two types of drug nanocarriers would offer a solution. Several research groups have developed polymer-lipid hybrid nanoparticles that possess controlled drug-release properties, high biocompatibility, and a favorable pharmacokinetic profile, representing a robust drug-delivery platform. ${ }^{19,24}$

We developed salinomycin-loaded polymer-lipid hybrid nanoparticles conjugated with anti-HER2 antibodies to promote the efficient delivery of salinomycin to breast CSCs and cancer cells. We isolated breast CSCs using aldehyde dehydrogenase (ALDH) as a breast CSC marker. ${ }^{25,26}$ The targeting efficacy and antitumor activity of the salinomycinloaded polymer-lipid anti-HER2 nanoparticles (Sali-NPHER2) against both breast CSCs and cancer cells were investigated.

\section{Materials and methods Reagents and cell lines}

Salinomycin sodium, poly(D,L-lactide-co-glycolide) (PLGA, 50:50, Mw 40,000-75,000 Da), bFGF, and EGF were purchased from Sigma-Aldrich (St Louis, MO, USA). Soybean lecithin was provided by Wako Pure Chemical
Industries, Ltd. (Osaka, Japan). The 1,2-distearoyl-snglycero-3-phosphoethanolamine- $N$-(methoxy(polyethylene glycol)-2000) (DSPE-PEG2000), 1,2-distearoyl-sn-glycero3-phosphoethanolamine- $N$-(maleimide(polyethylene glycol)-2000) (DSPE-PEG2000-Mal), and 1,2-dioleoylsn-glycero-3-phosphoethanolamine- $N$-carboxyfluorescein (ammonium salt) (CFPE) were purchased from Avanti Polar Lipids (Alabaster, AL, USA). Recombinant humanized antiHER2 monoclonal antibody (rhuMAb HER2) was kindly provided by the National Engineering Research Center for Antibody Medicine (Shanghai, China), and Fab' of rhuMAb HER2 (anti-HER2 Fab') was prepared as described previously. ${ }^{27}$ The secondary antibody, FITC-labeled goat anti-human $\operatorname{IgG}(\mathrm{H}+\mathrm{L})$, was provided by Zymed (South San Francisco, CA, USA). Traut's reagent (2-iminothiolane) was purchased from Pierce (Rockford, IL, USA). Roswell Park Memorial Institute (RPMI) 1640 medium, fetal bovine serum (FBS), B27, and insulin-transferrin-selenium (ITS) were provided by Thermo Fisher Scientific (Waltham, MA, USA). Cell Counting Kit-8 (CCK-8) was obtained from Dojindo (Kumamoto, Japan). All organic reagents of analytical grade were purchased from Sinopharm (Shanghai, China).

Human breast cancer cell lines BT-474 and MDAMB-361 were purchased from the American Type Culture Collection (ATCC, Manassas, VA, USA). BT-474 cells were grown in RPMI 1640 medium containing 10\% FBS, $2 \mathrm{mM}$ L-glutamine, $10 \mathrm{mM} \mathrm{N}$-2-hydroxyethylpiperazine- $N^{\prime}$-2ethanesulfonic acid (HEPES), $1 \mathrm{mM}$ sodium pyrophosphate, $4.5 \mathrm{~g} / \mathrm{mL}$ glucose, $1.5 \mathrm{~g} / \mathrm{mL}$ sodium carbonate, and $10 \mu \mathrm{g} / \mathrm{mL}$ insulin in a humidified atmosphere of $5 \% \mathrm{CO}_{2}$ at $37^{\circ} \mathrm{C}$. MDA-MB-361 cells were grown in Leibovitz's L-15 medium supplemented with $20 \%$ FBS in a humidified atmosphere of $5 \% \mathrm{CO}_{2}$ at $37^{\circ} \mathrm{C}$.

\section{HER2 expression of breast cancer cells}

Breast cancer cells were incubated with rhuMAb HER2 $(1 \mu \mathrm{g} / \mathrm{mL})$ for $30 \mathrm{~min}$ at $4^{\circ} \mathrm{C}$, and then rinsed and incubated with FITC-labeled goat anti-human IgG for $30 \mathrm{~min}$ at $4^{\circ} \mathrm{C}$. Cellular HER 2 expression, as reflected by the percentage of HER2 positively stained cells and HER2 mean fluorescence intensity (MFI), was analyzed with a FACScan flow cytometer (BD, Franklin Lakes, NJ, USA).

\section{Identification and isolation of ALDH- positive $(\mathrm{ALDH}+)$ cells}

ALDH+ cells with high ALDH enzymatic activity were identified and sorted using the ALDEFLUOR kit (StemCell Technologies, Vancouver, BC, Canada) and FACSAria (BD). 
Briefly, cells were suspended in ALDH assay buffer containing ALDH substrate-BODIPY-aminoacetaldehyde (BAAA) and incubated at $37^{\circ} \mathrm{C}$ for $40 \mathrm{~min}$. To distinguish between ALDH+ and ALDH-negative (ALDH-) cells, a fraction of the cells was incubated under identical conditions in the presence of $50 \mathrm{mM}$ of the ALDH inhibitor diethylaminobenzaldehyde.

\section{Development of polymer-lipid hybrid nanoparticles}

The polymer-lipid hybrid nanoparticles were developed by a one-step process of nanoprecipitation. ${ }^{19,24}$ Briefly, $2 \mathrm{mg}$ of salinomycin was dissolved with PLGA acetonitrile solution $(1 \mathrm{mg} / \mathrm{mL})$. After $0.5 \mathrm{mg}$ soybean lecithin and $0.15 \mathrm{mg}$ DSPE-PEG2000 were dissolved in a $4 \%$ ethanol aqueous solution heated to $65^{\circ} \mathrm{C}(1 \% \mathrm{CFPE}$ [molar ratio] was added for fluorescent nanoparticles), the PLGA acetonitrile solution was added into the preheated lipid aqueous solution dropwise ( $1 \mathrm{~mL} / \mathrm{min}$ ), followed by vortexing for $3 \mathrm{~min}$. The solution was stirred gently for $3 \mathrm{~h}$ at $25^{\circ} \mathrm{C}$. Next, free molecules and the remaining organic solvent were removed by dialysis against phosphate-buffered saline (PBS, pH 7.4) using a dialysis tube (Spectra/Por 6 membrane, MWCO 1,000; Spectrum Labs, Cincinnati, OH, USA). The nanoparticles were mixed with $3 \% \mathrm{w} / \mathrm{w}$ sucrose as a cryoprotectant and freeze-dried to obtain a fine powder.

The polymer-lipid hybrid anti-HER2 nanoparticles were prepared as described earlier, except that DSPE-PEG2000 was replaced by DSPE-PEG2000-Mal. Anti-HER2 Fab' was first thiolated by 2 -iminothiolane as described previously, ${ }^{28}$ and $0.5 \mathrm{mg}$ thiolated anti-HER2 $\mathrm{Fab}^{\prime}$ was mixed with $2 \mathrm{~mL}$ of the nanoparticles prepared earlier. The mixture was then incubated at $16^{\circ} \mathrm{C}$ overnight to form polymer-lipid hybrid anti-HER2 nanoparticles. Using Amicon ${ }^{\circledR}$ Ultra-4 centrifugal filter devices (Merck Millipore, Billerica, MA, USA), the unconjugated anti-HER2 Fab' was removed, collected, and quantitated using a BCA protein assay kit obtained from Biyuntian Biotechnology Research Institute (Haimen, China). The antibody conjugation efficiency was calculated as the percentage of conjugated antibody to the total amount of antibody added: conjugated antibody = total amount of added antibody - amount of unconjugated antibody in the flow-through liquid.

The following nanoparticles were designated: SaliNP-HER2, salinomycin-loaded polymer-lipid nanoparticles (Sali-NP), polymer-lipid anti-HER2 nanoparticles (NP-HER2), CFPE-labeled salinomycin-loaded polymerlipid anti-HER2 nanoparticles (CFPE-Sali-NP-HER2), and
CFPE-labeled salinomycin-loaded polymer-lipid nanoparticles (CFPE-Sali-NP).

\section{Physicochemistry of nanoparticles}

The size and zeta potential of nanoparticles were measured with a dynamic light-scattering detector (Zetasizer, Nano-ZS; Malvern Instruments, Malvern, UK). Nanoparticle morphology was assessed by transmission electron microscopy (TEM) (H-600; Hitachi, Tokyo, Japan).

\section{Drug encapsulation and loading efficacy of nanoparticles}

The drug encapsulation and loading efficacy of salinomycin in nanoparticles were measured by high-performance liquid chromatography (HPLC, L-2000; Hitachi), after the lyophilized nanoparticles were dissolved in dichloromethane. ${ }^{14} \mathrm{~A}$ reverse-phase C-18 column (Diamonsil, 250×4.6 mm, $5 \mu \mathrm{m}$; Dikma Technologies, Inc, Lake Forest, CA, USA) was used. The mobile phase was acetonitrile/deionized water/ tetrahydrofuran/phosphoric acid (85/10/5/0.01, v/v), and the flow rate was $1.5 \mathrm{~mL} / \mathrm{min}$. The detection wavelength and column temperature were $210 \mathrm{~nm}$ and $30^{\circ} \mathrm{C}$, respectively. Drug-loading efficiency was calculated as $M_{\mathrm{E}} / M_{\mathrm{N}} \times 100 \%$, with $M_{\mathrm{E}}$ being the mass of encapsulated drugs, and $M_{\mathrm{N}}$ being the mass of nanoparticles. The drug encapsulation efficiency was calculated as $M_{\mathrm{E}} / M_{\mathrm{T}} \times 100 \%$, with $M_{\mathrm{T}}$ being the mass of total drugs. The CFPE concentration in nanoparticles was calculated according to CFPE calibration curves constructed by standard lead CFPE solutions.

\section{In vitro drug release}

Five milliliters of nanoparticle solution were added to a dialysis tube (Spectra/Por 6 membrane, MWCO 1,000; Spectrum Labs). The sealed tube was inserted into a flask containing $1 \mathrm{~L}$ PBS with or without $10 \% \mathrm{FBS}$ in a $37^{\circ} \mathrm{C}$ water bath with stirring. One milliliter of the dialysate was taken out at different time points, and the salinomycin in the dialysate was determined as described earlier.

\section{Targeting efficacy of nanoparticles to breast cancer cells}

The targeting efficacy of nanoparticles to breast cancer cells was measured by flow cytometry and HPLC. For flow cytometry, breast cancer cells were seeded in 12-well plates with a density of $1 \times 10^{6}$ cells per well and incubated for $4 \mathrm{~h}$ with free CFPE, CFPE-Sali-NP, or CFPE-Sali-NP-HER2 (CFPE concentration: $50 \mathrm{ng} / \mathrm{mL}$ ). In the competitive assay, $50 \mathrm{mg} / \mathrm{mL}$ 
of anti-HER2 $\mathrm{Fab}^{\prime}$ was preincubated with the cells for $30 \mathrm{~min}$, before treatment with CFPE-Sali-NP-HER2. Next, the cells were analyzed using a FACScan flow cytometer. For HPLC analysis, breast cancer cells were seeded in 12-well plates with a density of $1 \times 10^{6}$ cells per well overnight. The cells were then incubated with free salinomycin, Sali-NP, or SaliNP-HER2 at a concentration of $50 \mu \mathrm{g} / \mathrm{mL}$ salinomycin for $4 \mathrm{~h}$. In the competitive assay, $50 \mathrm{mg} / \mathrm{mL}$ of anti-HER2 Fab' was preincubated with the cells for $30 \mathrm{~min}$, before treatment with Sali-NP-HER2. Next, the cells were rinsed 3 times with PBS, trypsinized, and harvested by adding $0.5 \mathrm{~mL}$ methanol. After sonication using a probe-type sonicator for $1 \mathrm{~min}$, the cell lysate was centrifuged, and the salinomycin content in the supernatant was measured by HPLC as described earlier. The protein concentration in the cell lysate was measured using a BCA protein assay kit. Salinomycin was quantified as the mass of salinomycin associated with the cells divided by the mass of cellular protein.

\section{Cell proliferation assays}

Cells were seeded at a density of $1 \times 10^{4}$ cells per well in 96-well plates for $12 \mathrm{~h}$ and treated with a series of concentrations of nanoparticles or salinomycin for $72 \mathrm{~h}$. Absorbance was used to measure cell viability using a microplate reader (Multiskan MK3; Thermo Fisher Scientific).

\section{Effect of treatments on CSC proportion in breast cancer cells}

Breast cancer cells were seeded at a density of $2 \times 10^{5}$ per well in 12-well plates for $12 \mathrm{~h}$. The cells were incubated with nanoparticles or $5 \mu \mathrm{g} / \mathrm{mL}$ salinomycin for $48 \mathrm{~h}$. Next, cells were rinsed to remove free drug, and further incubated for 3 days. The proportion of ALDH+ cells was analyzed by FACSAria using the method described earlier. Alternatively, the cells were removed from the culture plate and cultured at a density of 200 cells per well in ultra-low adherent 96-well plates (Corning Incorporated, NY, USA) to generate tumorspheres. The cell culture is stem cell-conditioned culture medium, which consists of DMEM-F12 with $20 \mathrm{ng} /$ $\mathrm{mL}$ bFGF, $20 \mathrm{ng} / \mathrm{mL}$ EGF, $1 \times$ B2 7 , and $1 \times$ ITS. After 7 days, the number of tumorspheres was counted under an inverted light microscope. The tumorspheres possess solid and round structures, and the cells appear fused together. The rate of tumorsphere formation was defined as the tumorsphere number formed in 7 days in the treatment group divided by the tumorsphere number formed in 7 days in the untreated group. The rate of tumorsphere formation in the untreated group was used as a control and defined as $100 \%$.

\section{Animal studies}

Mice (female, 4-6 weeks, $20 \mathrm{~g}$ ) were purchased from the Experimental Animal Center of Shandong (Jinan, China). All procedures were approved by the Committee on Animals of Liaocheng University (Shandong, China), and all procedures were performed in accordance with the guidelines of the Committee on Animals of Liaocheng University (Shandong, China).

\section{In vivo antitumor assay}

The antitumor assay was performed on mice bearing breast cancer xenografts as described below. Briefly, $5 \times 10^{6}$ BT-474 cells were injected subcutaneously into BALB/c nude mice (day 0). By day 10, the tumor growth was visible $\left(\sim 50 \mathrm{~mm}^{3}\right)$. From day 10 , mice were injected with nanoparticles $(7.5 \mathrm{mg}$ salinomycin $/ \mathrm{kg}$, intravenous) through the tail vein. Salinomycin (7.5 mg salinomycin $/ \mathrm{kg}$ ) dissolved in ethanol was administered by intraperitoneal injection. Therapy was given once every 2 days for a total of nine times. The tumor volume was calculated as (width ${ }^{2} \times$ length) $/ 2$ and monitored. The effect of the drugs on the CSC proportion was evaluated on day 28. After the mice were euthanized, the tumors were excised, and the CSC proportion of the tumor cells was evaluated by analyzing the proportion of ALDH+ cells and tumorsphere formation assay as described earlier.

\section{Statistical analysis}

Data were analyzed using SPSS 13.0 (IBM SPSS, Armonk, NY, USA). Direct comparisons between two groups were conducted using Student's non-paired $t$-test, and one-way analysis of variance (ANOVA) with the Newman-Keuls method was used to compare the mean values of three or more groups. $P<0.05$ was considered statistically significant.

\section{Results HER2 expression in breast cancer cells}

The ALDH+ cells with high ALDH enzymatic activity were identified and sorted by flow cytometry. As shown in Figure $1 \mathrm{~A}$ and B, 79\% of MDA-MB-361 cells were ALDH+, and $67 \%$ of BT-474 cells were ALDH+. As shown in Figure 1C, HER2 was found to be expressed in nearly $100 \%$ of the breast cancer cells, indicating that HER2 is highly expressed in breast cancer cells. To quantify HER2 expression intensity in breast cancer cells, the MFI of HER2 was used as an evaluation index (Figure 1D). The HER2 MFI in BT-474 cells increased 3-fold compared with that of MDAMB-361 cells. Notably, we found a positive correlation 
A

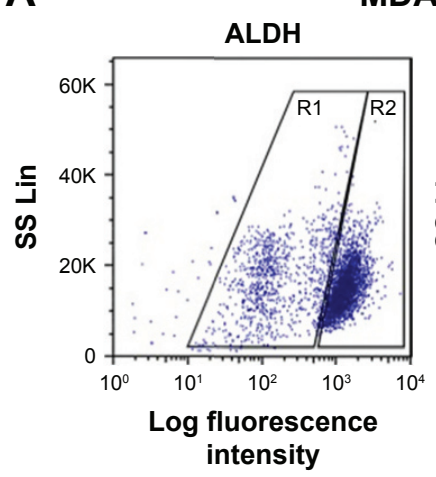

MDA-MB-361

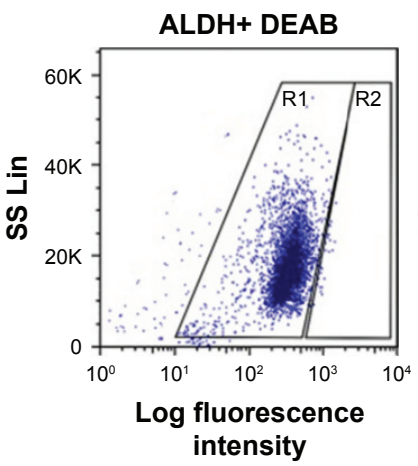

B

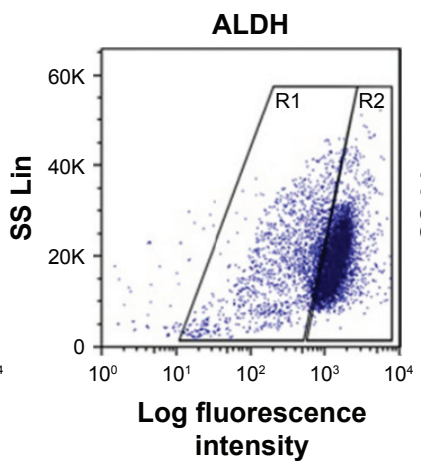

BT-474

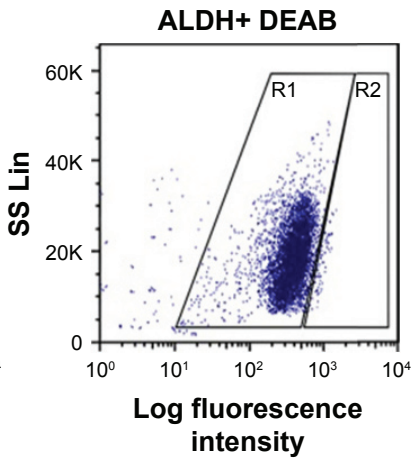

C

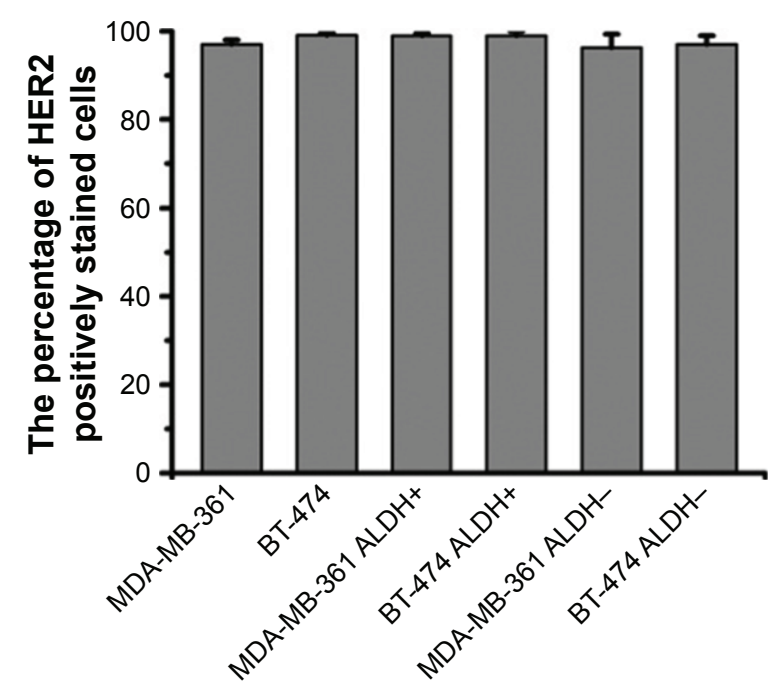

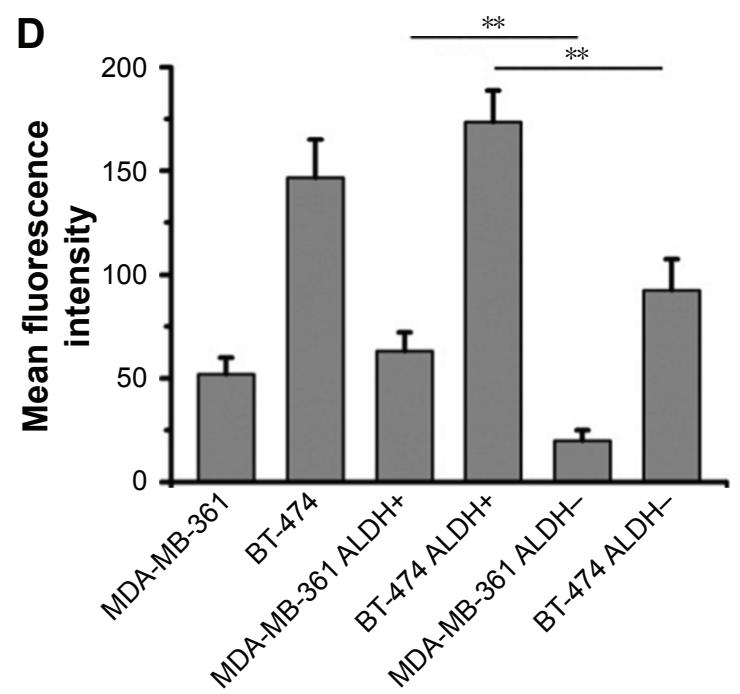

Figure I Expression of HER2 in breast cancer cells, analyzed by flow cytometry.

Notes: Representative fluorescence-activated cell sorting analysis of (A) MDA-MB-36I and (B) BT-474 cells tested by ALDEFLUOR assay. In the right image (ALDH+ DEAB), cells incubated with ALDH substrate (BAAA) and the specific inhibitor of ALDH, DEAB, were used to establish the baseline fluorescence of these cells (RI) and to define the ALDEFLUOR-positive region (R2). (C) Percentage of HER2 positively stained cells in breast cancer cells. (D) HER2 mean fluorescence intensity in breast cancer cells. Data are expressed as mean \pm SD $(n=3)$. $* * P<0.01$.

Abbreviations: ALDH, aldehyde dehydrogenase; BAAA, BODIPY-aminoacetaldehyde; DEAB, diethylaminobenzaldehyde.

between ALDH activity and HER2 cell surface expression. ALDH+ cells from MDA-MB-361 cells showed a 2.7-fold higher HER2 MFI than the ALDH- population $(P<0.01)$ (Figure 1D). Similar results were obtained with ALDH+ BT-474 cells, which showed a 2-fold higher HER2 MFI compared with the ALDH- population.

\section{Preparation and characteristics of nanoparticles}

A one-step nanoprecipitation process was adopted to develop Sali-NP, and Sali-NP-HER2 was further prepared by conjugating anti-HER2 Fab' with Sali-NP by a maleimide-thiol reaction, with an antibody conjugation efficiency of $24 \%$ (Figure 2A). As shown in Table 1, the size of the SaliNP-HER2 nanoparticles was $135.6 \mathrm{~nm}$, slightly larger than Sali-NP $(123.2 \mathrm{~nm})$. The polydispersity index of the nanoparticles was lower than 0.2 , meaning that their size distribution was homogeneous. The encapsulation efficiency of both nanoparticles was $\sim 55 \%$, and their drug-loading efficiency was higher than $8 \%$, indicating that the nanoprecipitation is effective for encapsulating salinomycin in nanoparticles. The TEM analysis indicated that both types of nanoparticles had a spherical shape, and the dim ring around the core demonstrated the well-defined core-shell structure of the nanoparticles (Figure 2B).

As shown in Figure 2C, both types of nanoparticles showed an initial burst of $\sim 50 \%$ in the first $12 \mathrm{~h}$. In the following $84 \mathrm{~h}$, the cumulative release reached $80 \%$. Both types exhibited slightly faster release in PBS with $10 \%$ FBS than in PBS alone after $24 \mathrm{~h}(P<0.05)$. Altogether, both types of nanoparticles exhibited sustained drug release during a period of $96 \mathrm{~h}$. 
A
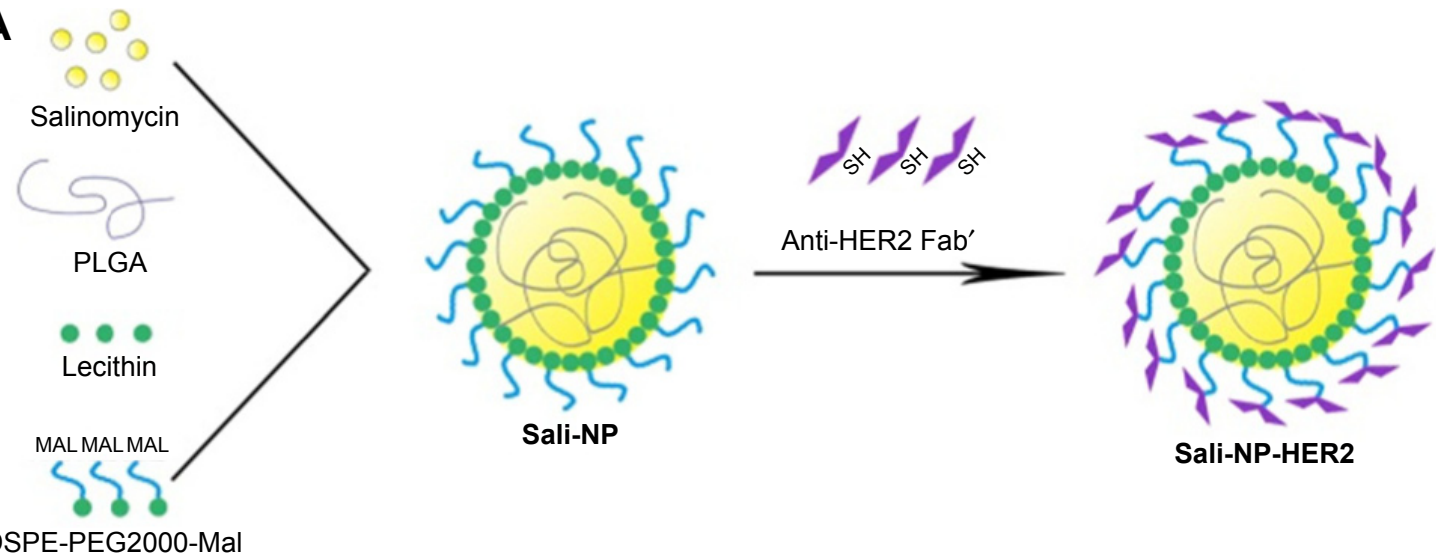

DSPE-PEG2000-Mal

B

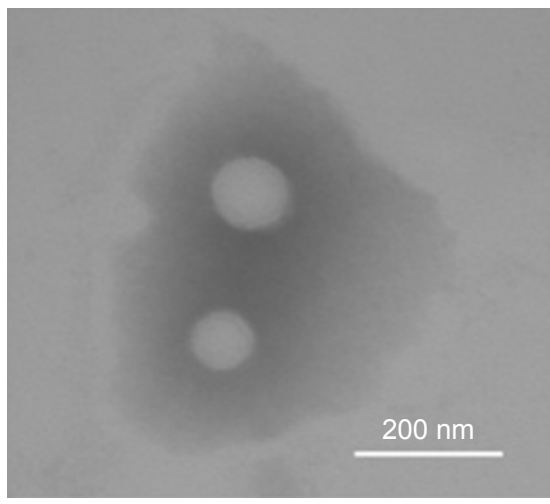

C

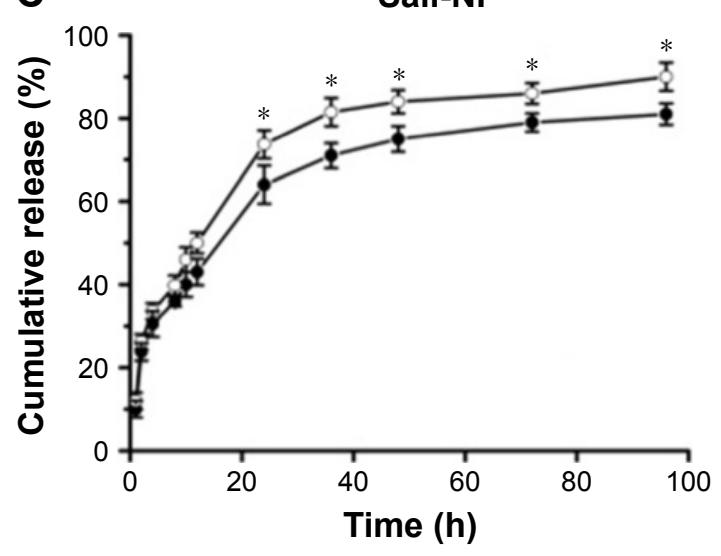

\section{Sali-NP-HER2}

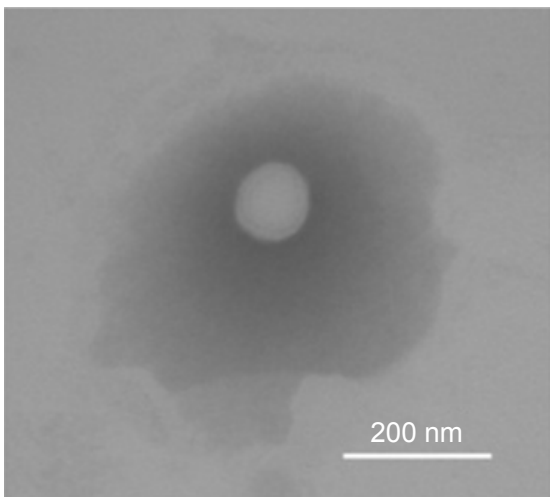

Sali-NP-HER2

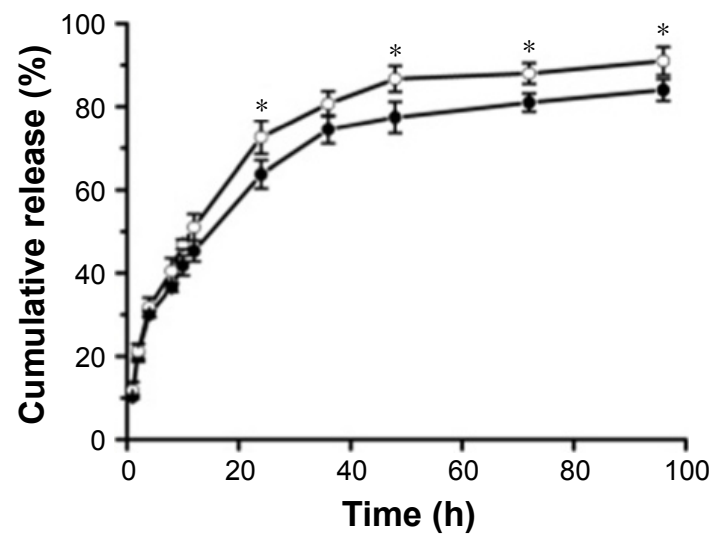

PBS $\multimap$ PBS $+10 \%$ FBS

Figure 2 Nanoparticle development, morphology, and drug release.

Notes: (A) Nanoparticle preparation. (B) TEM image of nanoparticles. Bars represent $200 \mathrm{~nm}$. (C) Cumulative salinomycin release from the nanoparticles in PBS or PBS with $10 \%$ FBS. The two groups were compared by Student's non-paired $t$-test at various time points. Data are expressed as mean $\pm S D(n=3)$. $* P<0.05$.

Abbreviations: FBS, fetal bovine serum; PBS, phosphate-buffered saline; PLGA, poly(D,L-lactide-co-glycolide); Sali-NP, salinomycin-loaded polymer-lipid nanoparticles; Sali-NP-HER2, salinomycin-loaded polymer-lipid hybrid anti-HER2 nanoparticles; TEM, transmission electron microscopy.

\section{Targeting efficacy of nanoparticles in breast cancer cells}

We used flow cytometry to evaluate the targeting efficacy of the nanoparticles (Figure 3A and B). In MDA-MB-361 ALDH+ and ALDH- cells, the MFI of the CFPE-Sali-NPtreated group was significantly higher than that of the
CFPE-treated group $(P<0.05$ in MDA-MB-361 ALDH+ cells; $P<0.001$ in MDA-MB-361 ALDH-cells), suggesting that the nanoparticles had significantly increased targeting efficacy than free drugs (Figure 3A). Notably, the MFI of the CFPE-Sali-NP-HER2-treated group was higher than that of the CFPE-Sali-NP-treated group $(P<0.01)$ and decreased 
Table I Characterization of nanoparticles

\begin{tabular}{llllll}
\hline Nanoparticles & $\begin{array}{l}\text { Size } \\
(\mathbf{n m})\end{array}$ & $\begin{array}{l}\text { Zeta } \\
\text { potential } \\
(\mathbf{m V})\end{array}$ & PDI & $\begin{array}{l}\text { Drug } \\
\text { loading } \\
(\%)\end{array}$ & EE (\%) \\
\hline Sali-NP & $123.2 \pm \mid 4.1$ & $-25.6 \pm 4.2$ & $0.12 \pm 0.06$ & $8.8 \pm 2.7$ & $59.2 \pm 9.3$ \\
Sali-NP-HER2 & $135.6 \pm \mid 7.6$ & $-28.3 \pm 5.8$ & $0.15 \pm 0.03$ & $8.0 \pm 3.9$ & $55.4 \pm 8.5$ \\
\hline
\end{tabular}

Note: Data are expressed as mean \pm SD $(n=3)$.

Abbreviations: EE, encapsulation efficacy; PDI, polydispersity index; Sali-NP, salinomycin-loaded polymer-lipid nanoparticles; Sali-NP-HER2, salinomycin-loaded polymer-lipid hybrid anti-HER2 nanoparticles.

after pretreatment with anti-HER2 Fab' $(P<0.01)$, suggesting that anti-HER2 $\mathrm{Fab}^{\prime}$ could efficiently increase the targeting efficacy of Sali-NP-HER2. With respect to BT-474 cells, similar results were gained (Figure 3B). CFPE-Sali-NPHER2 exhibited significantly increased targeting efficacy compared with CFPE-Sali-NP in both BT-474 ALDH+ and ALDH- cells $(P<0.001$ in BT-474 ALDH+ cells; $P<0.01$ in BT-474 ALDH- cells).

Furthermore, the salinomycin concentration in the SaliNP-treated group was significantly higher than that of the salinomycin-treated group in both MDA-MB-361 ALDH+ and ALDH-cells $(P<0.05)$ (Figure 3C). Notably, the salinomycin concentration in the Sali-NP-HER2-treated group was significantly higher than in the Sali-NP-treated group $(P<0.01)$ and decreased substantially after pretreatment with anti-HER2 $\mathrm{Fab}^{\prime}(P<0.05)$, indicating that anti-HER2 Fab' can efficiently increase the quantity of cell-associated salinomycin in SaliNP-HER2. Similar results were observed in BT-474 cells (Figure 3D).
A

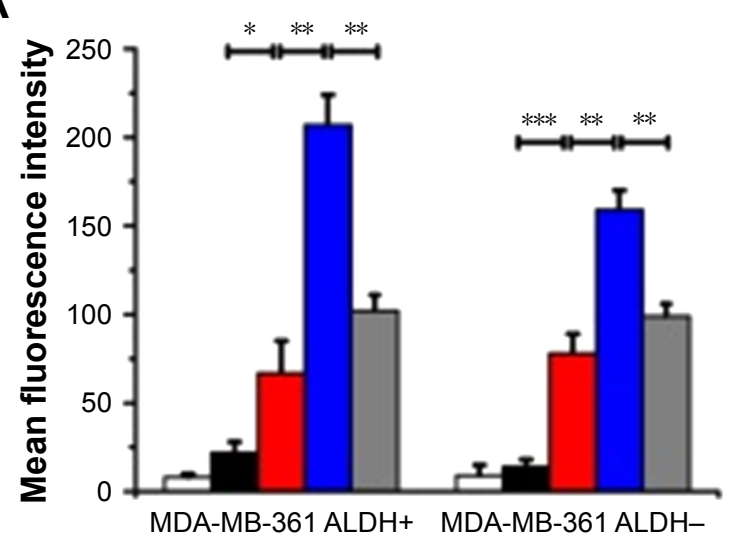

B

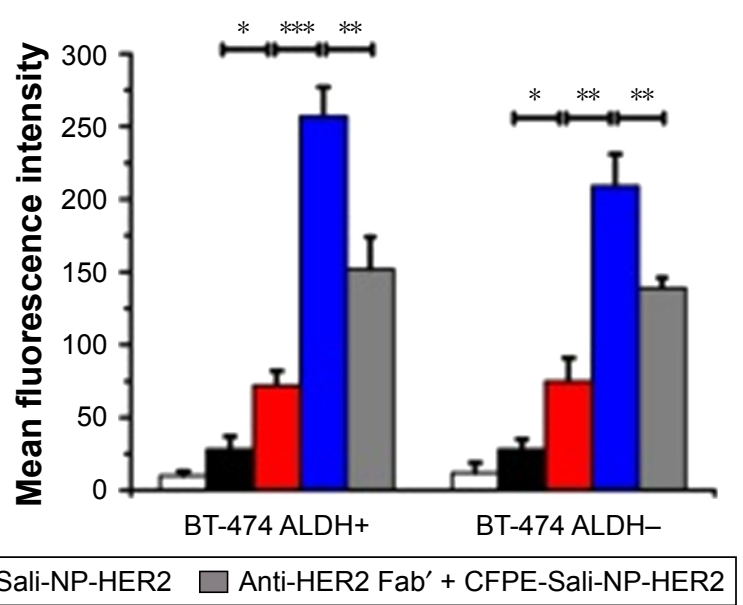

\section{$\square$ Untreated $\square$ Free CFPE $\square$ CFPE-Sali-NP $\square$ CFPE-Sali-NP-HER2 $\square$ Anti-HER2 Fab' + CFPE-Sali-NP-HER2}
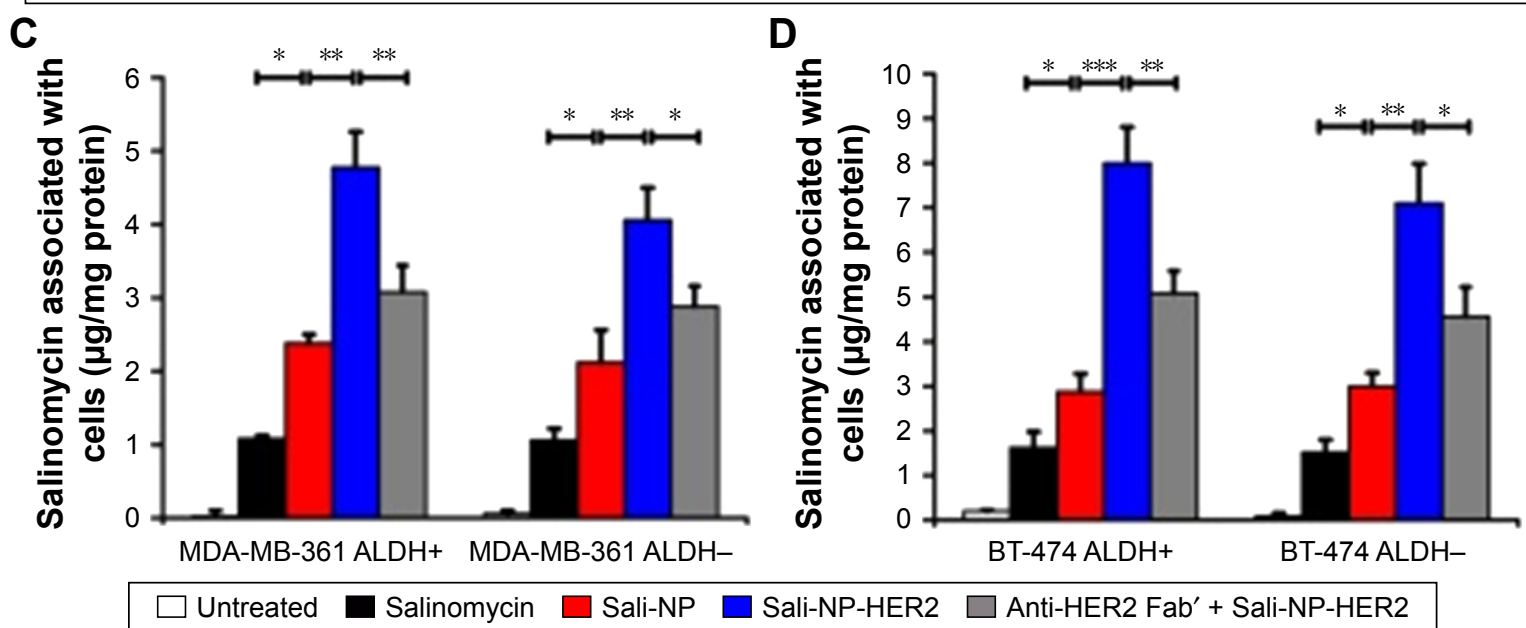

Figure 3 In vitro cellular uptake of nanoparticles in breast cancer cells.

Notes: (A and B) In vitro cellular uptake of nanoparticles, evaluated by flow cytometry. Breast cancer cells were incubated with free CFPE, CFPE-Sali-NP, or CFPE-Sali-NPHER2 for $4 \mathrm{~h}$. In the competitive assay (CFPE-Sali-NP-HER2 + anti-HER2 Fab'), $50 \mathrm{mg} / \mathrm{mL}$ of anti-HER2 Fab' was preincubated with the cells for 30 min prior to treatment with CFPE-Sali-NP-HER2. (C and D) In vitro cellular uptake of nanoparticles, evaluated by HPLC. Breast cancer cells were incubated with free salinomycin, Sali-NP, or Sali-NP-HER2 at a concentration of $50 \mu \mathrm{g} / \mathrm{mL}$ salinomycin for $4 \mathrm{~h}$. In the competitive assay (Sali-NP-HER2 + anti-HER2 Fab'), $50 \mathrm{mg} / \mathrm{mL}$ of anti-HER2 Fab' was preincubated with the cells for 30 min prior to treatment with Sali-NP-HER2. The intracellular uptake of salinomycin was calculated as intracellular salinomycin mass divided by cellular protein mass. Differences between groups were compared by one-way ANOVA and the Newman-Keuls method. Data are expressed as mean $\pm S D(n=3)$. $* P<0.05 ; * * P<0.01 ; * * * P<0.00$ I.

Abbreviations: ANOVA, analysis of variance; CFPE, I,2-dioleoyl-sn-glycero-3-phosphoethanolamine-N-carboxyfluorescein (ammonium salt); CFPE-Sali-NP, CFPE-labeled salinomycin-loaded polymer-lipid nanoparticles; CFPE-Sali-NP-HER2, CFPE-labeled salinomycin-loaded polymer-lipid anti-HER2 nanoparticles; HPLC, high-performance liquid chromatography; Sali-NP, salinomycin-loaded polymer-lipid nanoparticles; Sali-NP-HER2, salinomycin-loaded polymer-lipid hybrid anti-HER2 nanoparticles. 
In summary, nanoparticles facilitated the cellular delivery of salinomycin, and anti-HER2 Fab' further improved the targeting efficacy of nanoparticles in ALDH+ and ALDHbreast cancer cells.

\section{CCK-8 assay}

CCK-8 assays for nanoparticles and salinomycin were evaluated in ALDH+ and ALDH- breast cancer cells (Figure 4). NP-HER2, the anti-HER2 nanoparticles not containing salinomycin did not exhibit any cytotoxic effects, whereas salinomycin, Sali-NP, and Sali-NP-HER2 inhibited cellular proliferation in a concentration-dependent manner. Table 2 shows that in MDA-MB-361 ALDH+ cells, the half-maximal inhibitory concentration $\left(\mathrm{IC}_{50}\right)$ of Sali-NP-HER2 $(1.56 \mu \mathrm{g} / \mathrm{mL})$ was significantly lower than that of Sali-NP $(3.45 \mu \mathrm{g} / \mathrm{mL})$ $(P<0.05)$ and salinomycin $(7.98 \mu \mathrm{g} / \mathrm{mL})(P<0.01)$. In MDAMB-361 ALDH-cells, the $\mathrm{IC}_{50}$ of Sali-NP-HER2 $(7.80 \mu \mathrm{g} / \mathrm{mL})$ was significantly lower than that of Sali-NP $(18.35 \mu \mathrm{g} / \mathrm{mL})$ $(P<0.05)$ and salinomycin $(28.01 \mu \mathrm{g} / \mathrm{mL})(P<0.01)$. Thus, Sali-NP-HER2 was 2.2 and 5.1 times more effective than Sali-NP and salinomycin in MDA-MB-361 ALDH+ cells, respectively. In addition, Sali-NP-HER2 was 2.4 and 3.6 times more effective than Sali-NP and salinomycin in MDA-MB361 ALDH-cells, respectively. Similar results were obtained in BT-474 cells. Sali-NP-HER2 was 2.4 and 7.9 times more effective than Sali-NP and salinomycin in BT-474 ALDH+

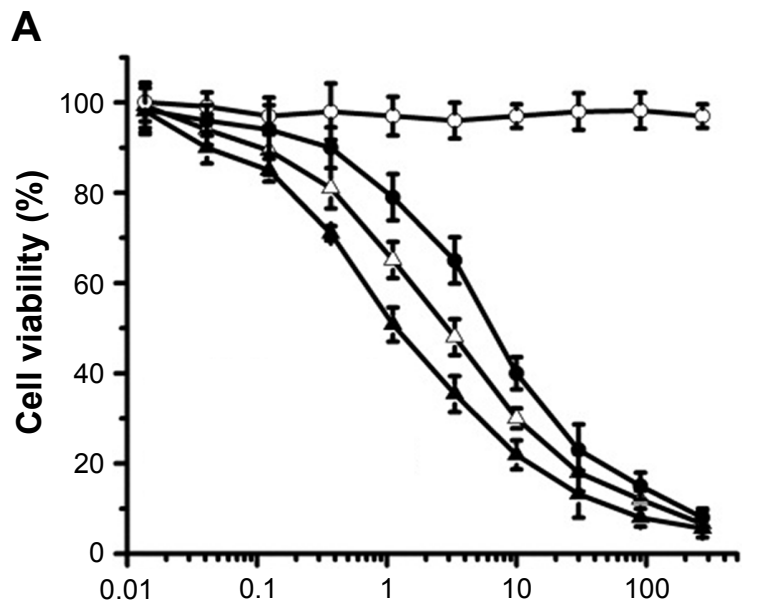

Concentrations of salinomycin $(\mu \mathrm{g} / \mathrm{mL})$

C

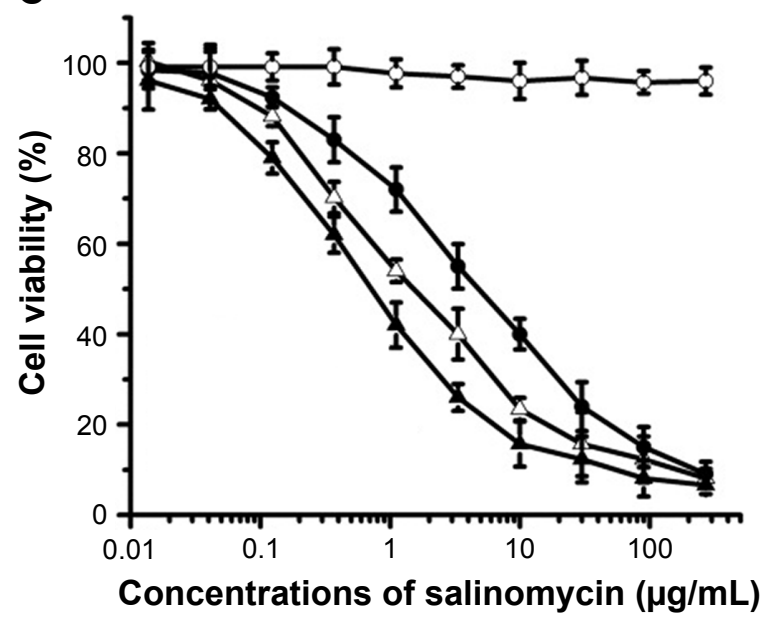

B

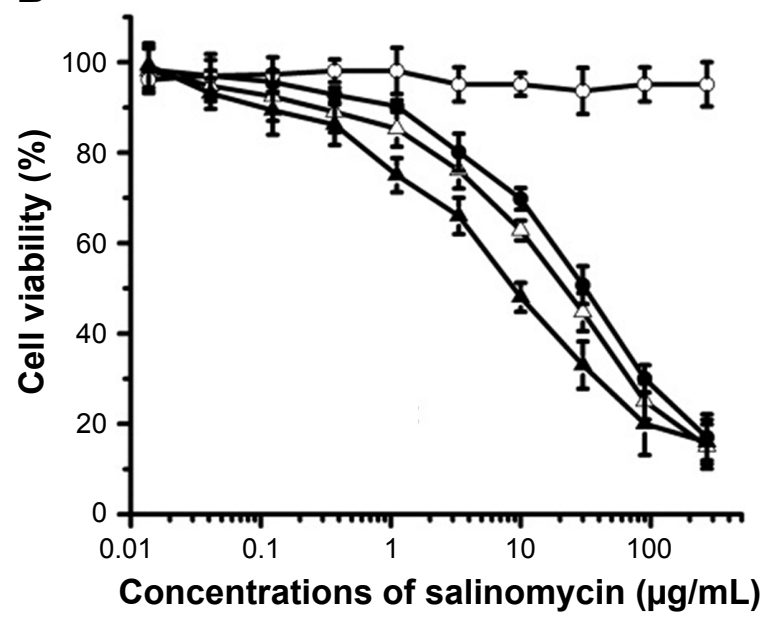

D

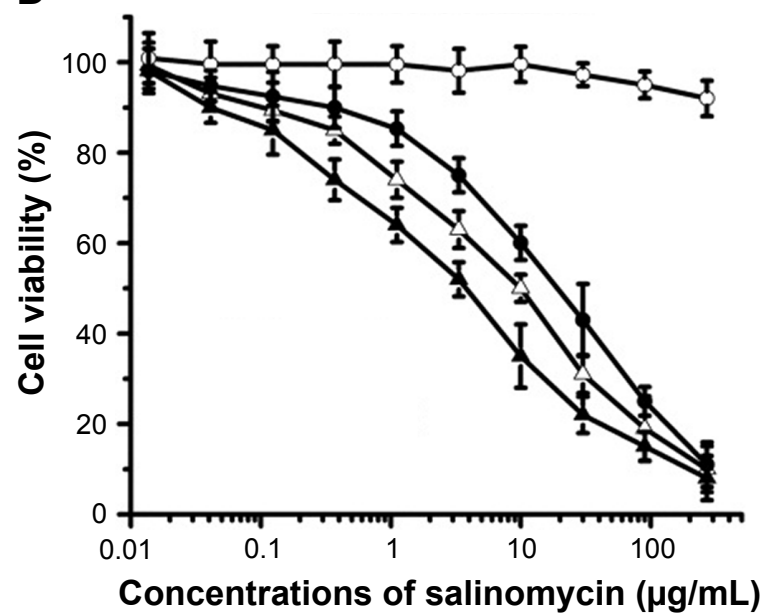

$\rightarrow$ Salinomycin $\sim$ Sali-NP $\sim$ Sali-NP-HER2 $\sim$ NP-HER2

Figure 4 Cell proliferation assay.

Notes: $\mathrm{ALDH}+$ and ALDH- breast cancer cells were seeded in 96-well plates with a density of I $\times 10^{4}$ cells per well overnight. The cells were incubated with the nanoparticles or salinomycin for $72 \mathrm{~h}$, and cell viability was evaluated using the CCK-8 assay. (A) MDA-MB-36I ALDH+, (B) MDA-MB-36I ALDH-, (C) BT-474 ALDH+, and (D) BT-474 ALDH-. Data are expressed as mean $\pm S D(n=3)$.

Abbreviations: ALDH, aldehyde dehydrogenase; CCK-8, Cell Counting Kit-8; Sali-NP, salinomycin-loaded polymer-lipid nanoparticles; Sali-NP-HER2, salinomycin-loaded polymer-lipid hybrid anti-HER2 nanoparticles. 
Table 2 The $\mathrm{IC}_{50}$ values of salinomycin and nanoparticles in breast cancer cells

\begin{tabular}{llllll}
\hline IC $_{50}(\mu \mathrm{g} / \mathrm{mL})$ & \multicolumn{2}{l}{ MDA-MB-36I } & & BT-474 & \\
\cline { 2 - 3 } & ALDH + & ALDH- & & ALDH + & ALDH- \\
\hline Salinomycin & $7.98 \pm 2.02$ & $28.01 \pm 5.16$ & & $5.97 \pm 1.6 \mathrm{I}$ & $20.6 \mathrm{I} \pm 5.44$ \\
Sali-NP & $3.45 \pm 0.73$ & $18.35 \pm 3.90$ & & $1.83 \pm 0.59$ & $10.29 \pm 3.6 \mathrm{I}$ \\
Sali-NP-HER2 & $1.56 \pm 0.43$ & $7.80 \pm 3.46$ & & $0.76 \pm 0.30$ & $5.18 \pm 1.87$ \\
NP-HER2 & $>250.0$ & $>250.0$ & & $>250.0$ & $>250.0$ \\
\hline
\end{tabular}

Note: Data are expressed as mean \pm SD $(n=3)$.

Abbreviations: $\mathrm{ALDH}$, aldehyde dehydrogenase; $\mathrm{IC}_{50}$, half-maximal inhibitory concentration; Sali-NP, salinomycin-loaded polymer-lipid nanoparticles; Sali-NPHER2, salinomycin-loaded polymer-lipid hybrid anti-HER2 nanoparticles.

cells, respectively. In BT-474 ALDH- cells, Sali-NP-HER2 was 2.0 and 4.0 times more effective than Sali-NP and salinomycin, respectively.

Furthermore, the $\mathrm{IC}_{50}$ of salinomycin in MDA-MB361 ALDH+ cells $(7.98 \mu \mathrm{g} / \mathrm{mL})$ was significantly lower than that of salinomycin in MDA-MB-361 ALDH- cells $(28.01 \mu \mathrm{g} / \mathrm{mL})(P<0.01)$, and the $\mathrm{IC}_{50}$ of salinomycin in BT-474 ALDH+ cells $(5.97 \mu \mathrm{g} / \mathrm{mL})$ was significantly lower than that of salinomycin in BT-474 ALDH- cells $(20.61 \mu \mathrm{g} / \mathrm{mL})(P<0.05)$, suggesting that salinomycin preferentially eliminated breast CSCs. The $\mathrm{IC}_{50}$ of Sali-NPHER2 in MDA-MB-361 ALDH+ cells $(1.56 \mu \mathrm{g} / \mathrm{mL})$ was significantly lower than that of Sali-NP-HER 2 in MDA-MB361 ALDH - cells $(7.80 \mu \mathrm{g} / \mathrm{mL})(P<0.05)$, and the $\mathrm{IC}_{50}$ of Sali-NP-HER2 in BT-474 ALDH+ cells $(0.76 \mu \mathrm{g} / \mathrm{mL})$ was significantly lower than that of Sali-NP-HER2 in BT-474 ALDH - cells $(5.18 \mu \mathrm{g} / \mathrm{mL})(P<0.05)$, suggesting that SaliNP-HER2 also preferentially eliminated breast CSCs.

Taken together, these findings suggest that Sali-NPHER 2 exhibits superior activity toward ALDH+ and ALDHbreast cancer cells and significantly enhanced cytotoxic effects toward breast CSCs, compared with common breast cancer cells.

\section{Effect of nanoparticles on the proportion of CSCs in breast cancer cells}

The effect of nanoparticles on the proportion of CSCs in breast cancer cell lines was examined by tumorsphere formation rate and the proportion of ALDH+ cells (Figure 5). The rate of tumorsphere formation in suspension cultures has been reported to correlate with the proportion of CSCs. ${ }^{13,14}$ As shown in Figure 5A and C, salinomycin significantly reduced the number of MDA-MB-361 tumorspheres relative to the untreated control $(P<0.05)$. Notably, Sali-NP-HER2 treatment resulted in a 4 -fold decrease in the number of MDA-MB-361 tumorspheres relative to the untreated control and also fewer tumorspheres compared with salinomycin treatment $(P<0.01)$ and Sali-NP treatment $(P<0.05)$. Consistently, Sali-NP-HER2 significantly decreased the proportion of ALDH+ cells in MDA-MB-361 cells compared with salinomycin $(P<0.01)$ and Sali-NP $(P<0.05)$ (Figure 5E). Similar results were obtained in BT-474 cells (Figure 5B, D, and F). Sali-NP-HER2 treatment resulted in a 5-fold decrease in the number of BT-474 tumorspheres and fewer tumorspheres than salinomycin treatment $(P<0.05)$ and Sali-NP treatment $(P<0.05)$ (Figure 5B and D). In addition, Sali-NP-HER2 significantly decreased the proportion of ALDH+ cells in BT-474 cells compared with salinomycin $(P<0.01)$ and Sali-NP $(P<0.05)$ (Figure 5F). Altogether, Sali-NP-HER2 showed enhanced therapeutic efficacy toward breast CSCs.

\section{Antitumor activity of nanoparticles in vivo}

Because of the lack of salinomycin, NP-HER2 exhibited no antitumor activity (Figure 6). Sali-NP-HER2 achieved the best therapeutic efficacy, resulting in a $79 \%$ decrease in tumor volume, whereas Sali-NP and salinomycin obtained only moderate therapeutic efficacy ( $63 \%$ decrease and $43 \%$ decrease, respectively). Tumor volume in the Sali-NPHER2-treated group was significantly smaller than tumor volume in other groups (Sali-NP-HER2 vs Sali-NP: $P<0.05$; Sali-NP-HER 2 vs salinomycin: $P<0.01$; Sali-NP-HER 2 vs NP-HER2: $P<0.001$; Sali-NP-HER2 vs saline: $P<0.001)$ (Figure 6A). Tumor weight was compared between the groups (Figure 6B and C). Tumor weight in the SaliNP-HER2-treated group was significantly lower than tumor weight in other groups (Sali-NP-HER2 vs Sali-NP: $P<0.01$; Sali-NP-HER2 vs salinomycin: $P<0.01$; Sali-NPHER2 vs NP-HER2: $P<0.001$; Sali-NP-HER2 vs saline: $P<0.001$ ).

The therapeutic efficacy of nanoparticles against breast CSCs was also evaluated (Figure 6D, E, and F). As expected, NP-HER2 did not affect tumorsphere formation of BT-474 cells compared with tumorsphere formation of the salinetreated control. Notably, Sali-NP-HER2 exhibited the best therapeutic efficacy against breast CSCs and induced a 4-fold decrease in BT-474 tumorsphere number relative to the saline control (Figure 6D). In addition, Sali-NP-HER2 treatment resulted in fewer tumorspheres compared with Sali-NP treatment $(P<0.05)$ and salinomycin treatment $(P<0.05)$. We also evaluated the proportion of ALDH+ breast cancer cells in the excised tumors (Figure 6E). Salinomycin significantly decreased the proportion of ALDH+ breast cancer 
A

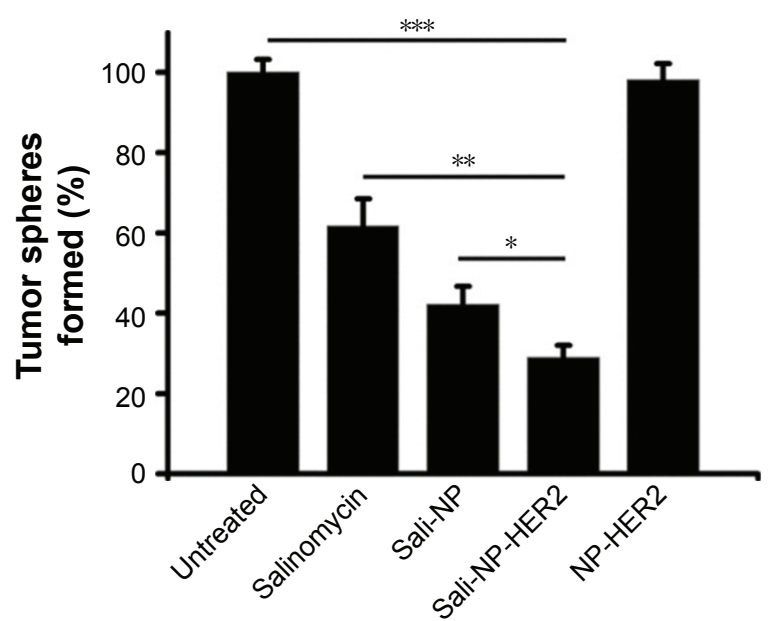

B

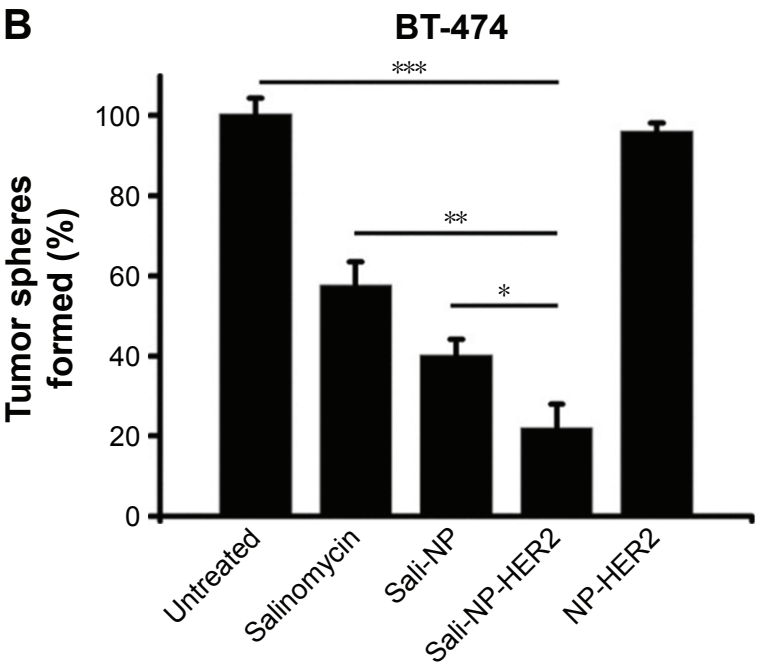

C

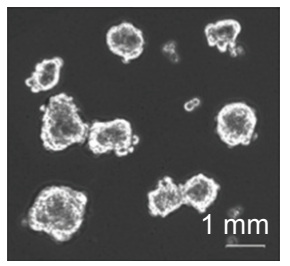

Untreated

D

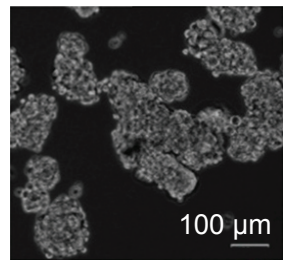

Untreated

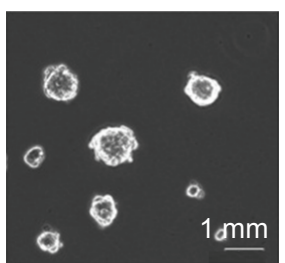

Salinomycin

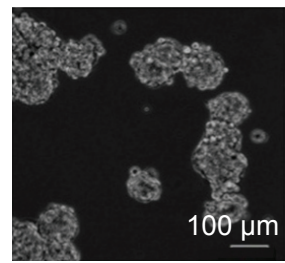

Salinomycin

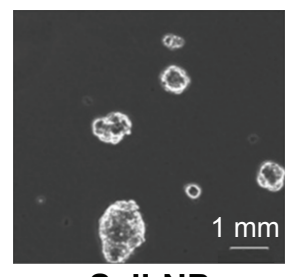

Sali-NP

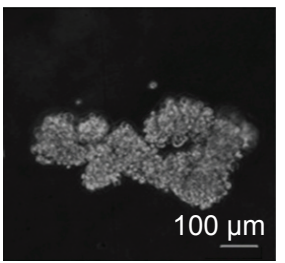

Sali-NP

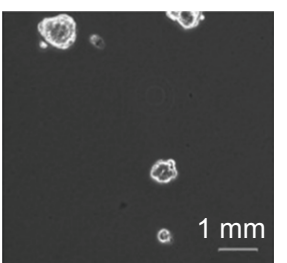

Sali-NP-HER2

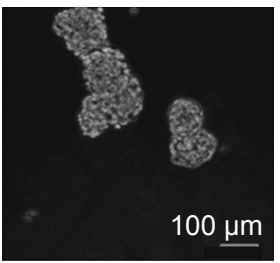

Sali-NP-HER2

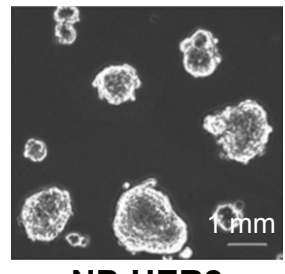

NP-HER2

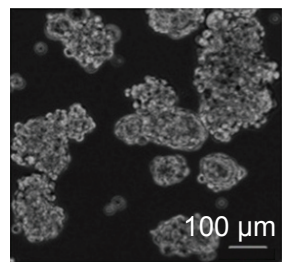

NP-HER2
E

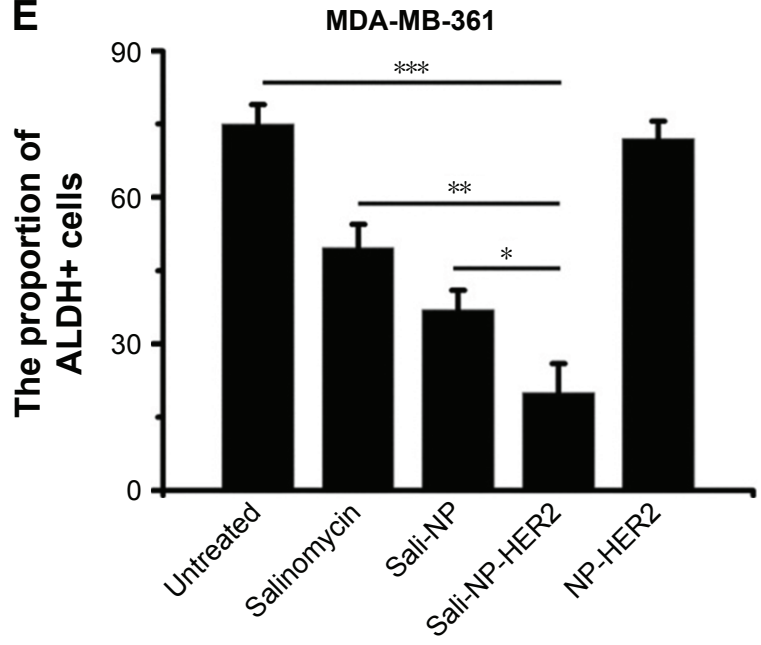

$\mathbf{F}$

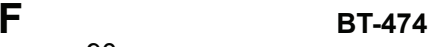

Figure 5 Effect of treatments on the percentage of CSCs.

Notes: Effect of the treatments on the proportion of CSCs in breast cancer cells, as reflected by the tumorsphere formation rate (A and $\mathbf{B})$ and the proportion of ALDH+ cells (E and $\mathbf{F}$ ). Representative images of tumorspheres formed by (C) MDA-MB-36I cells and (D) BT-474 cells are shown. The rate of tumorsphere formation is defined as the number of tumorspheres formed in 7 days in the treatment group divided by the number of tumorspheres formed in 7 days in the untreated group; the rate of tumorsphere formation in the untreated group is used as a control and defined as 100\%. The two groups were compared by one-way ANOVA with the Newman-Keuls method. Data are expressed as mean $\pm S D(n=6)$. $* P<0.05 ; * * P<0.01 ; * * * P<0.001$.

Abbreviations: ANOVA, analysis of variance; ALDH, aldehyde dehydrogenase; CSCs, cancer stem cells; Sali-NP, salinomycin-loaded polymer-lipid nanoparticles; NP-HER2, polymer-lipid anti-HER2 nanoparticles; Sali-NP-HER2, salinomycin-loaded polymer-lipid hybrid anti-HER2 nanoparticles. 
A

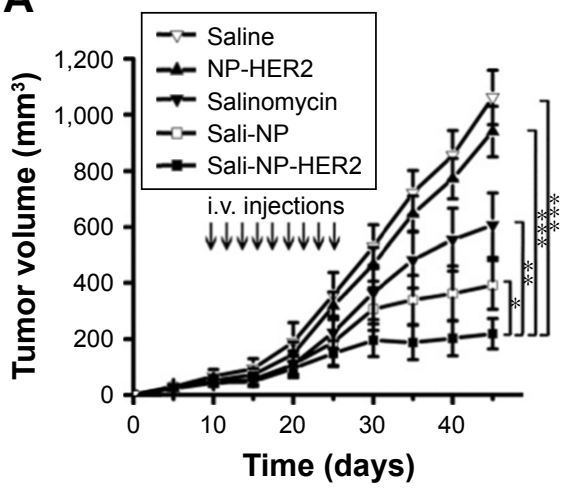

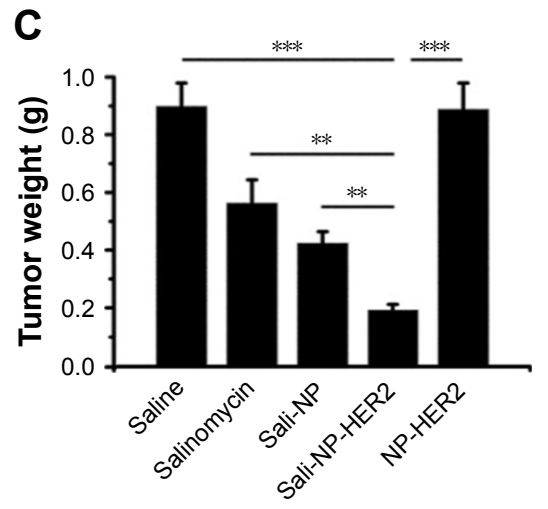

B

D

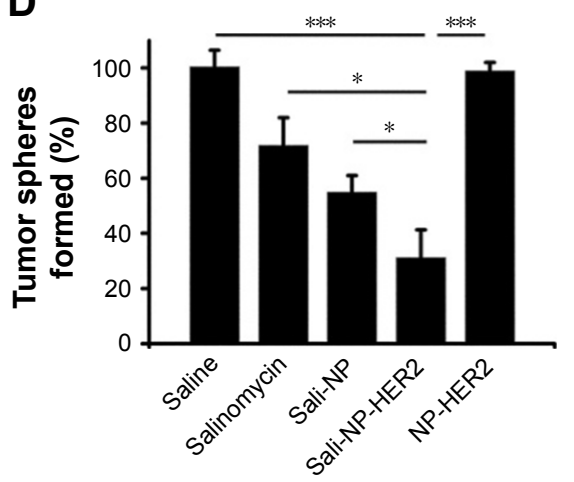

Saline

NP-HER2

Salinomycin

Sali-NP

Sali-NP-HER2

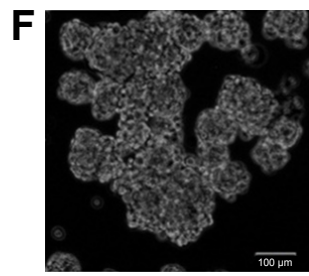

Saline

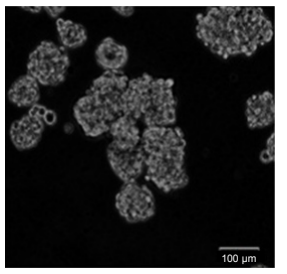

Salinomycin

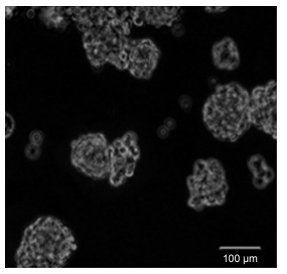

Sali-NP

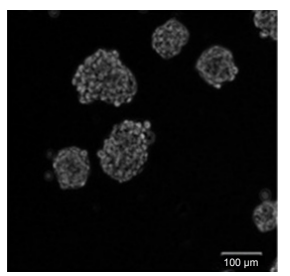

Sali-NP-HER2
E

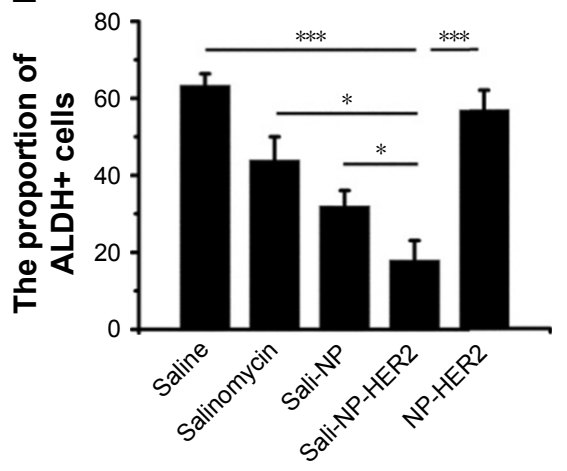

Figure 6 In vivo antitumor assay in mice bearing subcutaneous BT-474 tumors.

Notes: BT-474 tumors reached $\sim 50 \mathrm{~mm}^{3}$ in size by day 10. From day 10 , mice were injected with nanoparticles (7.5 mg salinomycin/kg, i.v.) through the tail vein, and salinomycin ( $7.5 \mathrm{mg}$ salinomycin/ $/ \mathrm{kg}$ ) dissolved in ethanol was administered by intraperitoneal injection. Therapy was given nine times on alternate days (indicated by arrows), and tumor volume was calculated. (A) Tumor growth curve. (B) Excised tumors. (C) The excised tumors were weighed at the end point. On day 28 , the effect of the drug treatments on the CSC proportion in BT-474 tumors in vivo was evaluated by (D) the rate of tumorsphere formation and (E) the proportion of ALDH+ cells from the excised tumors. (F) Representative images of tumorspheres from (D) are shown. The two groups were compared by one-way ANOVA with the Newman-Keuls method. Data are expressed as mean \pm SD $(n=8)$. $* P<0.05 ; * * P<0.01$; *** $P<0.001$.

Abbreviations: ANOVA, analysis of variance; ALDH, aldehyde dehydrogenase; CSC, cancer stem cell; i.v., intravenous; Sali-NP, salinomycin-loaded polymer-lipid nanoparticles; NP-HER2, polymer-lipid anti-HER2 nanoparticles; Sali-NP-HER2, salinomycin-loaded polymer-lipid hybrid anti-HER2 nanoparticles.

cells compared with the saline control $(P<0.05)$. Sali-NPHER2 treatment decreased the proportion of ALDH+ breast cancer cells more efficiently than salinomycin $(P<0.05)$ and Sali-NP $(P<0.05)$. The relative proportion of the ALDH+ breast cancer cells was 3-fold lower after treatment with Sali-NP-HER2 than after treatment with saline. Thus, SaliNP-HER2 efficiently decreased the population of breast CSCs in vivo.

\section{Discussion}

The treatment of breast cancer is a priority in public health. To maximize therapeutic efficacy, both breast CSCs and cancer cells must be eliminated. We constructed Sali-NPHER2 to achieve effective salinomycin delivery to HER2overexpressing breast CSCs and cancer cells.

The components of Sali-NP-HER2, including PLGA, soybean lecithin, DSPE-PEG2000, and anti-HER2 antibodies, are all US Food and Drug Administration-approved materials or drugs. Salinomycin was tested in a pilot clinical trial and exhibited good safety. ${ }^{9,13}$ We expect Sali-NP-HER2 to exhibit good safety as well, as required for nanoparticles in clinical use. ${ }^{29}$

We found that HER2 was substantially expressed in both breast CSCs and cancer cells, and more importantly, HER2 expression increased significantly in breast CSCs compared 
with breast cancer cells. Our results were consistent with those of previous studies, in which breast CSCs exhibited increased HER2 levels compared with common breast cancer cells. ${ }^{6,8}$ Since HER 2 expression in normal mammary epithelial cells or breast cancer cells enhances the tumorinitiating cell component driving tumorigenesis, invasion, and metastasis, it is plausible that HER2 expression would increase in breast CSCs compared with breast cancer cells. ${ }^{8,32}$ Thus, HER2 represents not only a promising target in breast cancer cells but also in breast CSCs.

CSCs emerge as a promising target in cancer therapy, and development of efficient CSC-specific therapies may enhance survival rates. ${ }^{25}$ Nanoparticles show potential against CSCs because of their controlled and targeted drug delivery and efficient pharmacokinetics and biodistribution. ${ }^{30}$ Targeted nanoparticles could improve drug delivery to cancer cells. ${ }^{17-19}$ Similarly, targeted nanoparticles with CSC marker-specific ligands are expected to preferentially eliminate CSCs. Wang et al developed single-walled carbon nanotubes (SWNTs) with CD133 mAb (anti-CD133-SWNTs) to target glioblastoma CD133+ cells. ${ }^{31}$ However, targeted nanoparticles with CSC marker-specific ligands may spare the bulk cancer cells which do not express CSC markers. ${ }^{25}$ Considering that sufficient evidence has established that cancer cells can spontaneously turn into CSCs, the common marker overexpressed in both CSCs and cancer cells is a promising target. HER2 has also been found to be overexpressed in breast CSCs in HER2-overexpressing cancer cells. ${ }^{8,22}$ Thus, HER 2 could be used to target both breast CSCs and cancer cells. Our data showed that the presence of an anti-HER2 antibody was crucial in maintaining the targeting efficacy of Sali-NP-HER2 in HER2-overexpressing breast CSCs and cancer cells. Flow cytometry and HPLC showed that Sali-NPHER2 could efficiently target HER2-overexpressing breast CSCs and cancer cells, resulting in enhanced cytotoxic effect compared with Sali-NP or salinomycin. In mice bearing BT-474 breast cancer xenografts, administration of Sali-NPHER2 displayed superior efficacy in inhibiting tumor growth compared with Sali-NP and salinomycin. Sali-NP-HER2 inhibited breast CSCs more effectively than Sali-NP and salinomycin both in vitro and in vivo. The superior activity of Sali-NP-HER2 is attributable to the targeting efficacy but not the intrinsic activity of the conjugated HER2 antibody. In our study, NP-HER2, the blank polymer-lipid hybrid anti-HER2 nanoparticles, did not exhibit cytotoxic effects on breast cancer cells and did not affect the proportion of CSCs in breast cancer cells. Importantly, in the mice bearing breast cancer xenografts, NP-HER2 did not exhibit any antitumor activity compared with the saline control.

\section{Conclusion}

HER2 is a target for drug delivery to both breast CSCs and cancer cells. Sali-NP-HER2 represents a promising treatment for breast cancer by eliminating both breast CSCs and cancer cells.

\section{Acknowledgments}

This work was supported by the National Natural Science Foundation of China (81402512 and 81771964), Liaocheng Municipal Science and Technology Development Planning project (2014GJH11), Shandong Provincial Science and Technology Development Planning project (2014GGB019AF), Natural Science Foundation of Shandong Province, China (ZR2013HZ002 and ZR2016EL04), and Special Funds for the Construction of Taishan Scholars. We thank Sunlipo Biotech Research Center for Nanomedicine (Shanghai, China) for providing technical supports in the preparation of nanoparticles.

\section{Disclosure}

The authors report no conflicts of interest in this work.

\section{References}

1. Benson JR, Jatoi I. The global breast cancer burden. Future Oncol. 2012;8(6):697-702

2. Ferlay J, Héry C, Autier P, Sankaranarayanan R. Breast cancer epidemiology. In: Li C, editor. Global Burden of Breast Cancer. Vol. 12. New York: Springer; 2010:1-19.

3. Gonzalez-Angulo AM, Morales-Vasquez F, Hortobagyi GN. Overview of resistance to systemic therapy in patients with breast cancer. $A d v$ Exp Med Biol. 2007;608(1):1-22.

4. Scully OJ, Bay BH, Yip G, Yu Y. Breast cancer metastasis. Cancer Genomics Proteomics. 2012;9(5):311-320.

5. Reya T, Morrison SJ, Clarke MF, Weissman IL. Stem cells, cancer, and cancer stem cells. Nature. 2001;414(6859):105-111.

6. Kai K, Arima Y, Kamiya T, Saya H. Breast cancer stem cells. Breast Cancer. 2010;17(2):80-85.

7. Gupta PB, Onder TT, Jiang G, et al. Identification of selective inhibitors of cancer stem cells by high-throughput screening. Cell. 2009;138(4): 645-659.

8. Magnifico A, Albano L, Campaner S, et al. Tumor-initiating cells of HER2-positive carcinoma cell lines express the highest oncoprotein levels and are sensitive to trastuzumab. Clin Cancer Res. 2009;15(6): 2010-2021.

9. Naujokat C, Steinhart R. Salinomycin as a drug for targeting human cancer stem cells. J Biomed Biotechnol. 2012;2012(8):950658.

10. Yue W, Hamaï A, Tonelli G, et al. Inhibition of the autophagic flux by salinomycin in breast cancer stem-like/progenitor cells interferes with their maintenance. Autophagy. 2013;9(5):714-729.

11. Meacham CE, Morrison SJ. Tumour heterogeneity and cancer cell plasticity. Nature. 2013;501(7467):328-337.

12. Chaffer CL, Brueckmann I, Scheel C, et al. Normal and neoplastic nonstem cells can spontaneously convert to a stem-like state. Proc Natl Acad Sci U S A. 2011;108(19):7950-7955.

13. Mao X, Liu J, Gong Z, et al. iRGD-conjugated DSPE-PEG2000 nanomicelles for targeted delivery of salinomycin for treatment of both liver cancer cells and cancer stem cells. Nanomedicine (Lond). 2015; 10(17):2677-2695. 
14. Xie F, Zhang S, Liu J, et al. Codelivery of salinomycin and chloroquine by liposomes enables synergistic antitumor activity in vitro. Nanomedicine (Lond). 2016;11(14):1831-1846.

15. Krishnamurthy S, Ng VW, Gao S, Tan MH, Hedrick JL, Yang YY. Codelivery of dual drugs from polymeric micelles for simultaneous targeting of both cancer cells and cancer stem cells. Nanomedicine (Lond). 2015;10(18):2819-2832.

16. Brannon-Peppas L, Blanchette JO. Nanoparticle and targeted systems for cancer therapy. Adv Drug Deliv Rev. 2012;64(11):206-212.

17. Choi HS, Liu W, Liu F, et al. Design considerations for tumour-targeted nanoparticles. Nat Nanotechnol. 2010;5(1):42-47.

18. Gao J, Feng SS, Guo Y. Antibody engineering promotes nanomedicine for cancer treatment. Nanomedicine (Lond). 2010;5(8):1141-1145.

19. Gao J, Xia Y, Chen H, et al. Polymer-lipid hybrid nanoparticles conjugated anti-HER2 antibody for targeted drug delivery to hepatocellular carcinoma. Nanomedicine (Lond). 2014;9(2):279-293.

20. Yarden Y. Biology of HER2 and its importance in breast cancer. Oncology. 2001;61(2 suppl):1-13.

21. Herbst RS. Review of epidermal growth factor receptor biology. Int $J$ Radiat Oncol Biol Phys. 2004;59(2 suppl):21-26.

22. Liu S, Wicha MS. Targeting breast cancer stem cells. J Clin Oncol. 2010;28(25):4006-4012.

23. Gao J, Chen H, Song H, et al. Antibody-targeted immunoliposomes for cancer treatment. Mini Rev Med Chem. 2013;13(14):2026-2035.

24. Chan JM, Zhang L, Yuet KP, et al. PLGA-lecithin-PEG core-shell nanoparticles for controlled drug delivery. Biomaterials. 2009;30(8): 1627-1634.
25. Gao J, Li W, Guo Y, Feng SS. Nanomedicine strategies for sustained, controlled and targeted treatment of cancer stem cells. Nanomedicine (Lond). 2016;11(24):3261-3282.

26. Charafe-Jauffret E, Ginestier C, Iovino F, et al. Aldehyde dehydrogenase 1-positive cancer stem cells mediate metastasis and poor clinical outcome in inflammatory breast cancer. Clin Cancer Res. 2010; 16(1):45-55

27. Gao J, Kou G, Wang H, et al. PE38KDEL-loaded anti-HER2 nanoparticles inhibit breast tumor progression with reduced toxicity and immunogenicity. Breast Cancer Res Treat. 2009;115(1):29-41.

28. Gao J, Sun J, Li H, et al. Lyophilized HER2-specific PEGylated immunoliposomes for active siRNA gene silencing. Biomaterials. 2010; 31(9):2655-2664.

29. Ai J, Biazar E, Jafarpour M, et al. Nanotoxicology and nanoparticle safety in biomedical designs. Int J Nanomedicine. 2011;6:1117-1127.

30. Gao J, Guo Y, Feng SS. Nanomedicine for treatment of cancer stem cells. Nanomedicine (Lond). 2014;9(2):181-184.

31. Wang $\mathrm{CH}$, Chiou SH, Chou CP, Chen YC, Huang YJ, Peng CA Photothermolysis of glioblastoma stem-like cells targeted by carbon nanotubes conjugated with CD133 monoclonal antibody. Nanomedicine. 2011;7(1):69-79.

32. Korkaya H, Paulson A, Iovino F, Wicha MS. HER2 regulates the mammary stem/progenitor cell population driving tumorigenesis and invasion. Oncogene. 2008;27(47):6120-6130.
International Journal of Nanomedicine

\section{Publish your work in this journal}

The International Journal of Nanomedicine is an international, peerreviewed journal focusing on the application of nanotechnology in diagnostics, therapeutics, and drug delivery systems throughout the biomedical field. This journal is indexed on PubMed Central, MedLine, CAS, SciSearch $\AA$, Current Contents $₫ /$ Clinical Medicine,

\section{Dovepress}

Journal Citation Reports/Science Edition, EMBase, Scopus and the Elsevier Bibliographic databases. The manuscript management system is completely online and includes a very quick and fair peer-review system, which is all easy to use. Visit http://www.dovepress.com/ testimonials.php to read real quotes from published authors. 